\title{
Contrast-Enhanced Ultrasonography: A Recent Application for the Diagnosis and Treatment of Hepatocellular Carcinoma
}

\author{
Maruyama H, ${ }^{1}$ Yoshikawa M, ${ }^{1}$ Yokosuka $\mathrm{O}^{1}$ \\ 'Department of Medicine and Clinical Oncology, Chiba University Graduate School of Medicine, Chiba, Japan
}

\begin{abstract}
Hepatocellular carcinoma has a decisive influence on the prognosis of cirrhotic patients, and the use of imaging modalities is essential for the screening, diagnosis and treatment of hepatocellular carcinoma. Ultrasound plays a major role among them, because it provides real-time and noninvasive observation by a simple and easy technique. In addition, ultrasound-guided needle puncture methods are frequently required for the diagnosis and/or treatment process of hepatocellular carcinoma. The development of digital technology has led to the detectability of blood flow by color Doppler ultrasound, and the sensitivity for tumor vascularity has shown remarkable improvement with the introduction of microbubble contrast agents. Moreover, near real-time three-dimensional ultrasound images are now available. These advancements in the ultrasound field have led to rapid progress in hepatocellular carcinoma management, and continuing advances are expected. This article reviews the current application of contrast-enhanced ultrasound for hepatocellular carcinoma in clinical practice.
\end{abstract}

Key words: contrast agent, hepatocellular carcinoma, ultrasound

\section{INTRODUCTION}

Hepatocellular carcinoma (HCC) is increasing worldwide and is one of the most common carcinomas in the eastern part of Asia. ${ }^{1-2}$ As the prognosis of cirrhotic patients depends on the occurrence and progression of HCC, diagnosis and treatment of this neoplasm are major issues in clinical practice.

Recent advances in digital technologies have resulted in remarkable developments in the field of imaging modalities. Ultrasound (US) is one of the diagnostic tools that have shown significant improvement within the last decade. ${ }^{3}$ As for the diagnosis of liver tumors,
US examination has the advantages of real-time observation, simple technique and non-invasiveness. It is being used worldwide, and at a high frequency, as a first-step, reliable method for the diagnosis of liver tumors. Further, the application of microbubble contrast agents provides details of the hemodynamics, which are useful for the detection and characterization of liver tumors. ${ }^{4-5}$ Diagnosis and treatment of HCC have shown remarkable improvement with the clinical usage of contrast-enhanced US.

This article reviews the recent application of contrastenhanced US for the management of HCC.

\footnotetext{
Correspondence:

Dr. Hitoshi Maruyama

Department of Medicine and Clinical Oncology

Chiba University Graduate School of Medicine 1-8-1

Inohana, Chuou-ku, Chiba 260-8670, Japan.

Phone: $+81-43-2262083$

Email: maru-cib@umin.ac.jp
} 
Maruyama et al. Contrast-Enhanced Ultrasonography: A Recent Application for the Diagnosis and Treatment...

\section{Color Doppler US}

The advent of the Doppler method has turned around diagnostic ultrasound. . $-4,10-12$ The waveform analysis was the primary application, and it was frequently used for the characterization of liver tumors. Then, color flow imaging with real-time observation added to the diagnostic process of liver tumors, and power Doppler mode contributed to a better detectability of blood flow. ${ }^{13-21}$ However, limitations in the detection of slow flow and vessels deeply located from the skin surface have prevented the wider application of Doppler mode in the evaluation of tumor hemodynamics. Furthermore, artifacts caused by respiratory or cardiac motion sometimes affect the precise evaluation of hemodynamic information. At present, the application of Doppler mode alone for detecting tumor blood flow is rare, as the more recent availability of microbubble contrast agents has assisted in overcoming those limits.

\section{Microbubble contrast agents}

With the above as a background, there has been considerable expectation that US contrast agents would improve the detectability of blood flow in liver tumors. In fact, since the first report about a US contrast agent by Gramiak et al. There has been an ongoing challenge to establish a contrast-enhanced US with microbubble agents. ${ }^{22-25}$ While free gas bubbles are efficient scatterers of ultrasound, their utility has been limited because of their immediate removal by the lungs. From the late 1980s to the 1990s, greyscale contrast-enhanced US with carbon dioxide gained broad attention as an echo-enhancing technique, with high sensitivity for detecting tumor vascularity and high performance for the characterization of liver tumors. ${ }^{26}$ 27 However, the method requires an arteriography procedure because carbon dioxide is easily soluble in blood. The development of microbubble contrast agents available with peripheral venous injection was expected for practical use.

At the end of the 20th century, finally a galactosebased US contrast agent (SHU 508, Levovist) was made available by Schering, Germany. It was a long-awaited material that could provide a stable enhancement effect in abdominal organs with a peripheral injection. Subsequently, many microbubble contrast agents have been developed or are currently under development (Table 1). These intravenously injectable agents improve the detectability of tumor blood flow and the depiction of characteristic flow patterns in Doppler mode or contrast-specific imaging mode with less safety concerns.
Characteristic property of microbubble contrast agents

1. Acoustic properties of microbubble and specific imaging mode

The microbubble agents have characteristic acoustic properties that depend on the size and kind of gas and shell. ${ }^{5,28}$ Contrast harmonic imaging mode, which is based on non-linear scattering behaviors of microbubbles, provides high resolution with fewer artifacts compared to the simple Doppler technique, and is now a representative imaging method specialized for microbubble contrast agents. ${ }^{29-30}$

The behaviors of microbubbles are related to the acoustic power level (Ml; Mechanical Index) of the transmitted ultrasound. As for Levovist, US transmission under a standard acoustic power level for routine US examination provides immediate disappearance of the microbubbles. This feature, "loss of correlation" ("stimulated acoustic emission"), is used in some imaging modes specialized for Levovist. ${ }^{31-32}$ Additionally, the echo signal increases according to lengthening of the interval between frames, as the intermission during US transmission reduces the destruction of microbubbles in the region of interest (ROI) and help microbubble to gather in the US field. With this methodology, an ingenious contrivance of intermittent transmission technique has been developed to obtain strong echo-enhancement in the ROI as a contrast-specific imaging. ${ }^{33}$

The next-generation contrast agents, such as SonoVue (Bracco Diagnostics, Princeton, NJ, USA) and Definity (Bristol-Myers Squibb, N. Billerica, MA, USA), have characteristic oscillation behavior under very low $\mathrm{MI}$ which provides the fewer tissue signals and less microbubble breakdown. As a result, contrast harmonic imaging under low $\mathrm{Ml}$ level has received considerable attention of late as a useful method for real-time observation of microbubble images, and it is expected to improve the diagnostic ability of liver tumors (Fig. 1). ${ }^{34-38}$

\section{Accumulation property of microbubble}

The diagnostic performance of contrast-enhanced US is not limited to the demonstration of tumor vascularity. Some microbubble contrast agents have a characteristic property of organ-specific accumulation. ${ }^{36-39}$ Although the precise mechanism remains unclear, the reticuloendothelial system (i.e. phagocytosis by Kupffer cells) may be involved in this phenomenon. Both Levovist and Sonazoid (GE Healthcare, Oslo, Norway) accumulate in the liver, and sonograms in this phase (late liver-specific parenchymal phase) are frequently used for the 
Maruyama et al. Contrast-Enhanced Ultrasonography: A Recent Application for the Diagnosis and Treatment...

detection or characterization of liver tumors. In contrast, Definity and SonoVue do not accumulate in the liver. The characterization of liver tumors by contrast-enhanced US has been carried out using accumulation images as well as vascular enhancement images (Figure 2A, B).

\section{Clinical application of contrast-enhanced US}

\section{Detection of vascularity in HCC}

Microbubble contrast agents can increase the detectability of blood flow by US examination. Numata et al. reported that the same results in detecting tumor vascularity, 53/61 nodules (87\%), between contrast-enhanced harmonic grey-scale imaging with Levovist and helical CT. ${ }^{39}$ More recent studies also showed over $80 \%$ concordance of tumor vascularity (Giorgio et al., $82.4 \%$; Bolondi et al., $81 \%$ ) between contrast-enhanced US under low MI level with SonoVue, and contrast-enhanced helical CT. ${ }^{40-41}$ The improved detectability of tumor vascularity in contrast-enhanced US contributes to the characterization of liver tumors and assessment of the therapeutic response.

\section{Characterization of focal liver lesions}

Many studies using contrast-enhanced US have been carried out for the characterization of focal liver lesions with early-phase images and/or delayed phase (liver-specific phase) images (Figure 1, Table 2). Early-phase images provide characteristic vascular-enhancement patterns that are useful for specific diagnosis. ${ }^{42-44}$ However, evaluation of the enhanced appearance in delayed-phase images is not always simple owing to the fact that the accumulation property of microbubbles affects the enhancement findings in this phase. According to previous reports, focal nodular hyperplasia (FNH) shows positive enhancement and metastatic tumor shows negative enhancement in the delayed phase with Levovist, a contrast agent with accumulation property in the liver. ${ }^{45-48}$ However, it is known that several enhancement patterns are observed in both HCC and hepatic hemangioma in delayed phase sonograms. ${ }^{45-48}$ Despite the various kinds of contrast agents, evaluation of combined multi-phase images would improve the diagnostic ability of contrastenhanced US.

Concerning the discrimination of malignant versus benign liver lesions by contrast-enhanced US, recent literatures have reported sensitivity of 98 to $100 \%$ and specificity of 63 to $93 \%$ with Levovist, and sensitivity of $98 \%$ and accuracy of $92.7 \%$ with SonoVue. ${ }^{45-50}$ Furthermore, in a clinical study with two independent image reviewers, Kim et al. described that contrast-enhanced US (agent detecting imaging mode with Levovist) provided a specific diagnosis in $75-79 \%$ of 75 patients with focal hepatic lesions, and that the technique was successful as a confirmatory imaging technique in $63-72 \%$ of the patients. ${ }^{51}$

Small HCC nodules less than $20 \mathrm{~mm}$ sometimes present a hypovascular appearance by imaging modalities, and both dysplastic nodules and regenerative nodules also appear as hypovascular nodules. ${ }^{41,52-54}$ Since high-grade dysplastic nodules are considered as potentially pre-malignant lesions, the characterization of such hypovascular nodules is very important in clinical practice. ${ }^{55-56}$ The recent study reported that intensity analysis of contrast enhancement with Levovist was useful method for the characterization of non-hypervascular small hepatic nodules, regenerative nodule from HCC. ${ }^{57}$ However, the diagnostic ability of contrastenhanced US in the early diagnosis of HCC and discrimination of dysplastic nodules from HCC has not been established. At present, percutaneous needle biopsy under US-guidance may be frequently required for the characterization of small hepatic lesions in patients with chronic liver diseases.

Hypervascular hepatic lesions do not always reflect the fact that the final diagnosis of the nodule is $\mathrm{HCC}$ in heavy drinkers, since benign hypervascular nodules sometimes occur in their liver. ${ }^{58} \mathrm{~A}$ recent report has shown that the ring-shaped appearance on liver-specific contrast-enhanced sonograms with Levovist may be a useful sign for the differential diagnosis of benign nodule from HCC in heavy drinkers. ${ }^{59}$ Since contrast-enhanced CT hardly differentiates these benign nodules from HCC, this characteristic finding may prevent unnecessary treatments under misdiagnosis. Moreover, it could be expected to lead to a reduction in the application of percutaneous needle biopsy, an invasive procedure, for the precise diagnosis.

\section{Detection of tumor nodules in the liver}

Some kinds of hepatic nodules, such as metastatic liver tumors, appear as hypo-enhanced nodules on liver-specific images by accumulated microbubbles in the liver. Since grey-scale US sometimes fails to detect metastatic tumor nodules because of their small size and iso-echoic appearance, contrastenhanced liver-specific sonograms assist in detecting occult tumor nodules on grey-scale images. ${ }^{30,60-64}$ This application of US contrast agents contributes to the staging of the disease by a non-invasive procedure. 
Maruyama et al. Contrast-Enhanced Ultrasonography: A Recent Application for the Diagnosis and Treatment...

Meanwhile, as neither Definity nor Sonovue accumulate in the liver, they do not provide liverspecific phase which is useful to detect occult tumor nodules (blood-pool contrast agents). However, previous study showed that contrast-enhanced US with Definity improved the detection rate of hepatic tumors in rabbit liver. ${ }^{65}$ As a suitable MI for this agent is quite low level which allows less microbubble breakdown, repeated observation for contrastenhancement is possible. However, comparison of detectability of tumor nodules between the agent with accumulation property and the agent without accumulation property remains to be solved.

Recent US systems have provided three-dimensional visualization of the tumor with tumor-associated vessels at any plane from multiple directions. ${ }^{66}$ 69 Contrast-enhanced 3D ultrasonographies using microbubble contrast agents might become a standard method for the characterization of hepatic tumors (Figure 2).

Treatment support and evaluation of therapeutic effect

\section{Treatment of HCC}

\section{Percutaneous needle puncture technique}

As the majority of patients with HCC have liver dysfunction, surgery is not always an appropriate treatment choice..$^{2,70-71}$ In addition, recurrence of $\mathrm{HCC}$ is an inseparable companion of post-treatment patients. With such backgrounds, percutaneous ethanol injection (PEI) and radio-frequency ablation (RFA) were developed and came to be widely used in clinical practice as minimally invasive methods. ${ }^{72}$

77 They are now a first-line, favored approach that has an efficient therapeutic effect on HCC. ${ }^{78-84}$

\section{Problem for US-guided treatments}

Although percutaneous US-guided treatments provide sufficient therapeutic effect, recurrence often plagues many HCC patients. According to long-term study results, cumulative recurrence rates of the treated site of post-PEI lesions were $3.4 \%$ at 1 year, $7.1 \%$ at 2 years, and $10 \%$ at 3 years, and those of the untreated sites in liver were $18.7 \%$ at 1 year, $62.1 \%$ at 3 years, and $81.7 \%$ at 5 years, respectively. ${ }^{80}$ Thus, many HCC patients have to receive repeated treatments during their clinical course. In order to minimize adverse effects to the liver, less invasive treatment such as PEI or RFA is preferable for these patients. However, localization of lesions on the sonograms is sometimes problematic in patients with cirrhotic liver and/or repeated treatment history (Figure 3). ${ }^{85-86}$ Although percutaneous treatment under CT guidance is a well-established technique and a useful method for lesions undetected by US, the method lacks convenience and exposes both patients and physicians to radiation. ${ }^{87-90}$ Microbubble contrast agents are also useful in such a case. A recent study showed that contrast-enhanced US with Levovist could localize $24 / 32(75 \%)$ of HCC lesions that were invisible by non-contrast US. ${ }^{91}$ Application of the next-generation US contrast agents is expected to improve the ability for tumor localization, because they have acquired stability of microbubble homogenization of particle size distribution in comparison with earlier agents.5,92 Moreover, the combination of second-generation contrast agents with harmonic imaging mode under lower MI may produce US images with improved signal-to-noise ratio, and a higher detection rate of focal lesions in the liver is expected. ${ }^{36,49}$ The detectability of ultrasonically unrecognizable hypervascular HCC with Sonazoid, a newly developed perflubutane agent, was reported to be $96.4 \%$, which was quite higher than that with Levovist. ${ }^{93}$ Contrast-enhanced US with Sonazoid would widen the application of percutaneous US-guided treatments (Figure 4).

\section{Assessment of therapeutic response by ultrasound}

With high sensitivity and specificity for detecting tumor vascularity, contrast-enhanced US has come to be frequently applied for evaluation of the therapeutic response in HCC nodules (Table 3). As for percutaneous treatment, Bartolozzi et al. reported that contrast-enhanced color Doppler with Levovist showed sensitivity of $92 \%$, specificity of $100 \%$, and accuracy of $98 \%$ compared to the results of spiral CT and biopsy, in the detection of viable tumor treated with PEI. ${ }^{94} \mathrm{~A}$ study by Choi et al. revealed that the diagnostic agreement between contrast-enhanced power Doppler with Levovist 14-23 hours after ablation therapy and immediate follow-up CT within 30 minutes after ablation therapy was achieved in $100 \%$ of the 45 HCC nodules. ${ }^{95}$ In an assessment of therapeutic response after RFA, Wen et al. compared the result of contrast-enhanced coded harmonic angio mode with Levovist for detecting residual tumor in $91 \mathrm{HCC}$ nodules 5 to 7 days after RFA with that of dynamic CT, and the sensitivity, specificity, and diagnostic accuracy were $95.3 \%$, $100 \%$, and $98.1 \%$, respectively. ${ }^{96}$ According to the study by Meloni et al., the sensitivity and specificity of contrast-enhanced harmonic US with Levovist were $83.3 \%$ and $100 \%$, respectively, for detecting residual non-ablated tumor at 4 months after treatment in $43 \mathrm{HCC}$ nodules, compared with helical CT findings. ${ }^{97}$

As for assessment of the therapeutic response after transarterial chemoembolization (TACE), it is well known that contrast-enhanced US has the advantage of not being limited by iodized oil 
Maruyama et al. Contrast-Enhanced Ultrasonography: A Recent Application for the Diagnosis and Treatment...

Table 1. US contrast agents (quotation from World J Gastroenterol 2008;21:1710-9)

\begin{tabular}{lllll}
\hline & Gas & Shell & Diameter* & Manufacturer \\
\hline Al-700 & Perfluorocarbon & Synthetic polymer & $?$ & Acusphere \\
Albunex & Air & Cross-linked albumin & $3-5(4.3)$ & Molecular Biosystems \\
iosphere & Air & Biodegradable polymer & $?$ & Ponit Biomedical \\
Definity & perfluoropropane & Lipid & 2.3 & Bristol-Myers Squibb (DuPont Merck $\dagger$ ) \\
Echovist & Air & Galactose & 3 & Schering \\
Echo Gen & Dodecafluoropentane & Surfactant & $0.4,2-5 \ddagger$ & Sonus Pharmaceuticals \\
Imavist & Perfluorohexane & Surfactant & $<5$ & Alliance Pharmaceutical \\
Levovist & Air & Galactose Palmitic acid & 1.3 & Schering \\
Optison & Perfluoropropane & Cross-linked albumin & $3.6-5.4(4)$ & Molecular Biosystems \\
Sonavist & Air & Cyanoacrylate(polymer) & 1 & Schering \\
Sonazoid & Perfluorocarbon & Lipid & $2.4-2.5$ & Nycomed-Amersham \\
SonoVue & Sulfur Hexafluoride & Phospholipids & 2.5 & Bracco Diagnostics \\
uantison & Air & Albumin & 3.2 & Quadrant \\
\hline
\end{tabular}

*: Diameter of microbubble $(\mu \mathrm{m})$. Numbers in parentheses are mean diameters.

$t$ : Prior manufacturer

$\ddagger$ : Echo Gen is the first phase shift US contrast agent which has a boiling point significantly below body temperature. It has two different conditions, a liquid at room temperature (non echogenic particles with a mean diameter of approximately $0.4 \mu \mathrm{m}$ ) and a gas at body temperature (echogenic microbubbles with a diameter of 2-5 $\mu \mathrm{m}$ )

Table 2. Characterization of focal hepatic lesions by contrast-enhanced US

\begin{tabular}{|c|c|c|c|}
\hline Author & Contrast agent & No. of patients & Results* \\
\hline \multirow[t]{3}{*}{ Bryant TH, et al. [47] } & Levovist & 88 & Sensitivity§ 89, 93\% \\
\hline & & 54 & Specificity§ 80, 93\% \\
\hline & & 142 & Accuracy§ 88, 90\% \\
\hline \multirow[t]{2}{*}{ Dietrich CF, et al. [48] } & Levovist & 174 & Sensitivity $100 \%$ \\
\hline & & & Specificity 93\% \\
\hline \multirow[t]{4}{*}{ Kim SH, et al. [51] } & Levovist & 75 & Sensitivity§ 98, 98\% \\
\hline & & & Specificity§ 85, $91 \%$ \\
\hline & & & SD†,§ 75, 79\% \\
\hline & & & CIT $\ddagger, \S 63,72 \%$ \\
\hline \multirow[t]{2}{*}{ von Herbay A, et al.[45] } & Levovist & 67 & Sensitivity $100 \%$ \\
\hline & & & Specificity 63\% \\
\hline \multirow[t]{3}{*}{ Nicolau C, et al. [50] } & SonoVue & 152 & Sensitivity $98 \%$ \\
\hline & & & Specificity $82 \%$ \\
\hline & & & Accuracy $92.8 \%$ \\
\hline
\end{tabular}

\footnotetext{
*: Discrimination of benign and malignant lesions
}

t: Specific diagnosis: Correct diagnosis was obtained by contrast-enhanced US

¥: Confirmatory imaging technique: The reader judged that no further imaging for lesion characterization was needed and that the lesion concerned had been correctly diagnosed.

$\S$ : Evaluation by two different readers 
Maruyama et al. Contrast-Enhanced Ultrasonography: A Recent Application for the Diagnosis and Treatment...

Table 3. Assessment of therapeutic response after radiofrequency ablation (RFA) for HCC using contrast-enhanced US

\begin{tabular}{|c|c|c|}
\hline Author & No. of patients/ No. of lesions & Results* \\
\hline & & (contrast agent) \\
\hline \multirow[t]{3}{*}{ Wen et al [96] } & $67 / 91$ & Sensitivity $95.3 \%$ \\
\hline & & Specificity $100 \%$ \\
\hline & & Accuracy $98.1 \%$ (Levovist) \\
\hline \multirow[t]{2}{*}{ Meloni et al [97] } & $25 / 43$ & Sensitivity $83.3 \%$ \\
\hline & & Specificity 100\%(Levovist) \\
\hline Choi et al [95] & $40 / 45$ & Diagnostic agreement $100 \%$ (Levovist) \\
\hline Kim et al [101] & $90 / 94$ & Diagnostic concordant 99\% (Levovist) \\
\hline \multirow[t]{3}{*}{ Solbiati et al [102] } & $20 / 20$ & Sensitivity $50 \%$ \\
\hline & & Specificity $100 \%$ \\
\hline & & Diagnostic agreement $85 \%$ (Levovist) \\
\hline
\end{tabular}

*: Comparison with contrast-enhanced helical CT

†: 1-month follow-up CT

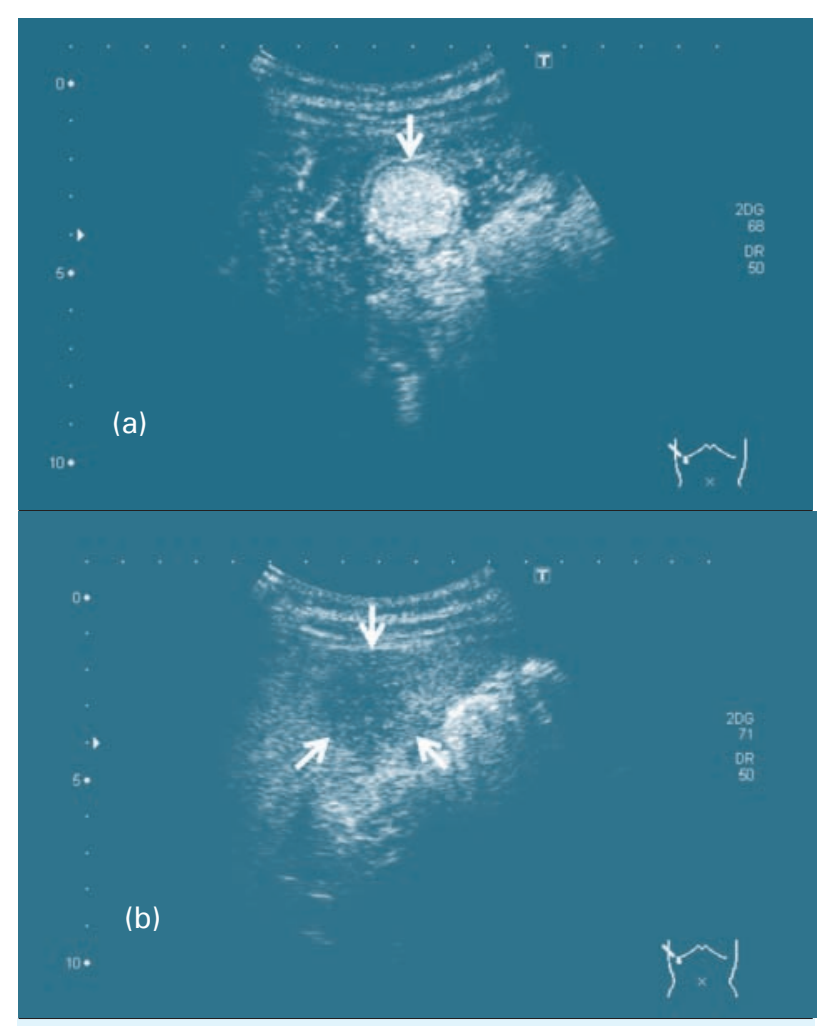

Figure 1. Contrast-enhanced harmonic imaging with Sonazoid in HCC (26.3 mm, arrows)
a) Early-phase image (27 seconds after the injection)
b) Late-phase image (10 minutes after the injection)

The early-phase image showed positive enhancement and the late-phase image showed negative enhancement in the nodule. These findings provided easy diagnosis of HCC.

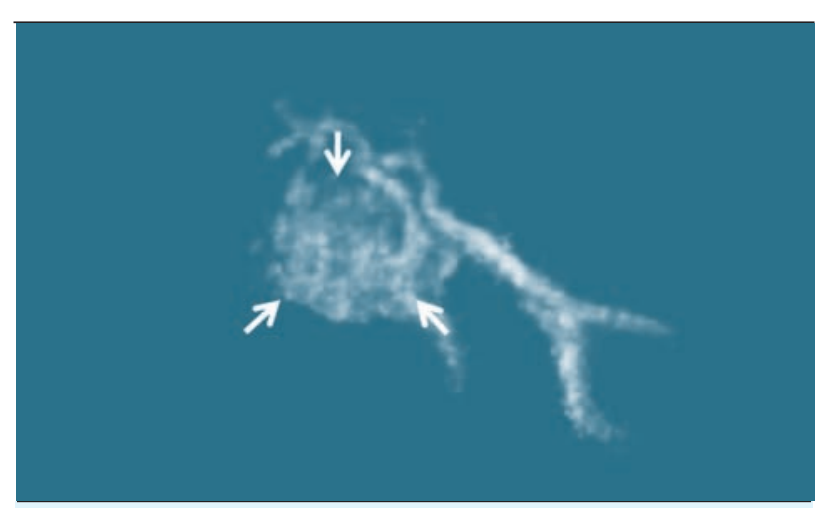

Figure 2. Three-dimensional ultrasonography (contrast-enhanced 3DUS with Sonazoid, arrows) showed hypervascular tumor with abundant fine tumor vessels.

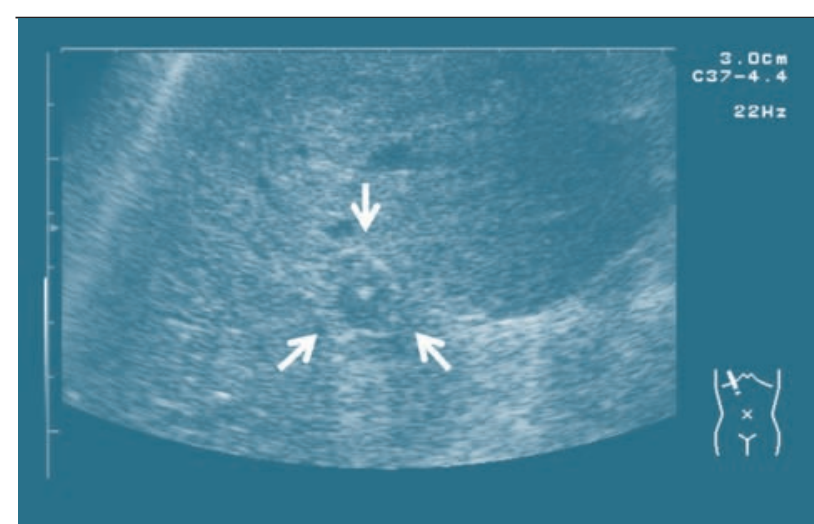

Figure 3 (a). HCC (S8, $29.4 \mathrm{~mm}$ ), local recurrence of HCC after PEI B-mode US

Treated area of HCC after PEI (arrows)

There was no identification whether the tumor was viable or not. 
Maruyama et al. Contrast-Enhanced Ultrasonography: A Recent Application for the Diagnosis and Treatment...

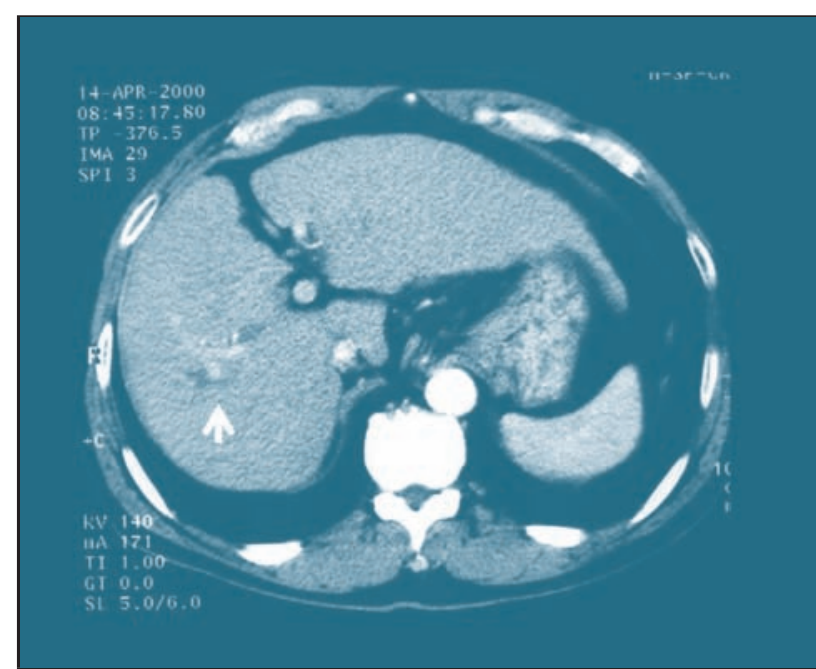

3 (b). Contrast-enhanced CT

Contrast enhancement at the local recurrence lesion was observed in the treated area (arrow).

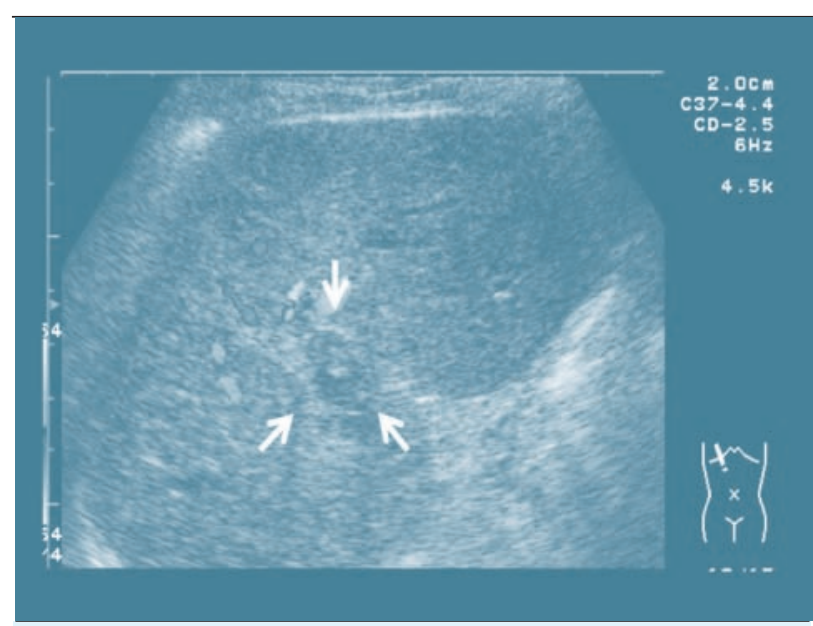

\section{3 (c). Color Doppler US}

No findings appeared in the treated area on the image (arrows).

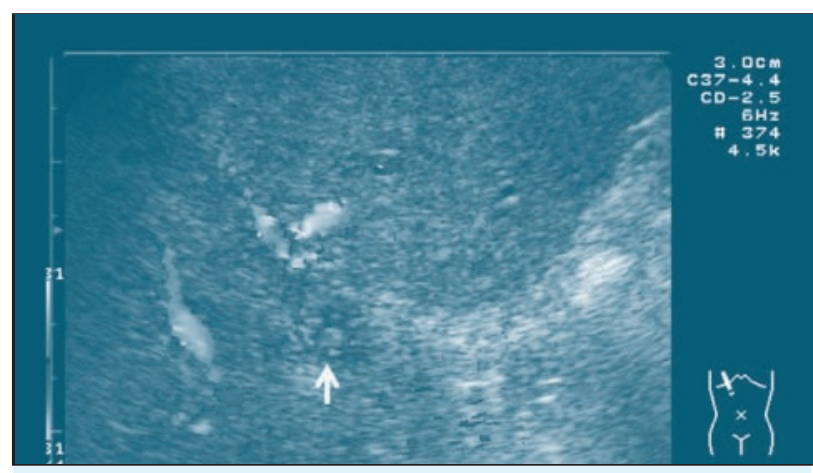

3 (d). Contrast-enhanced US with Levovist

Contrast-enhanced color Doppler could demonstrate a blood flow which was similar to contrast-enhanced CT finding (arrow).

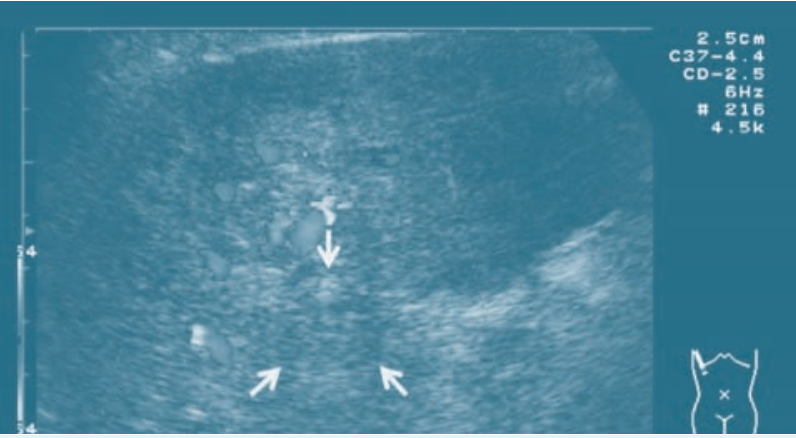

3 (e). Contrast-enhanced US with Levovist after PEI

Color flow signal disappeared after the treatment.

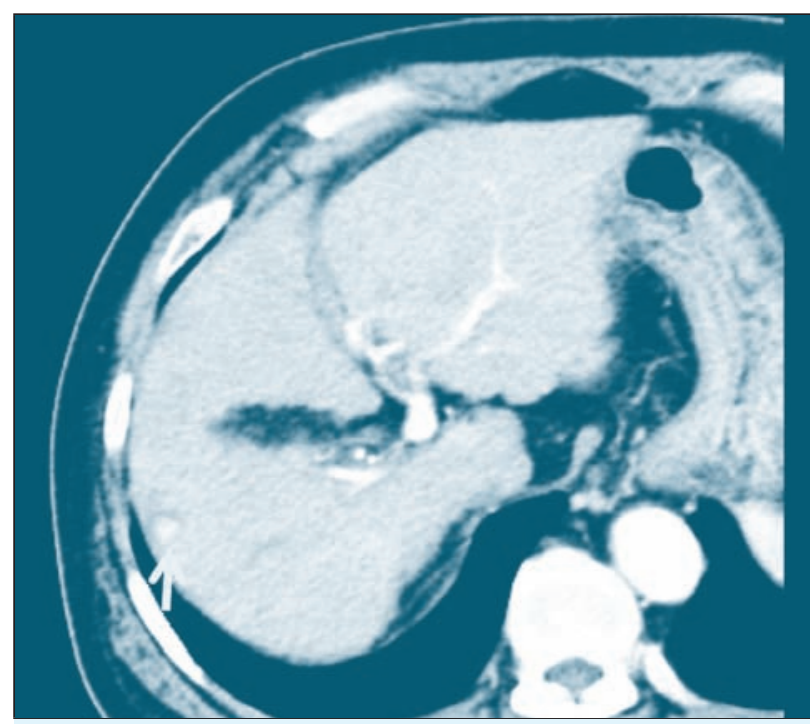

Figure 4 (a). Detection of ultrasonically invisible hypervascular HCC using contrast-enhanced US with Sonazoid a) Contrast-enhanced CT

Hypervasuclar lesion which was local recurrence of HCC was observed on contrast-enhanced CT image (arrow).

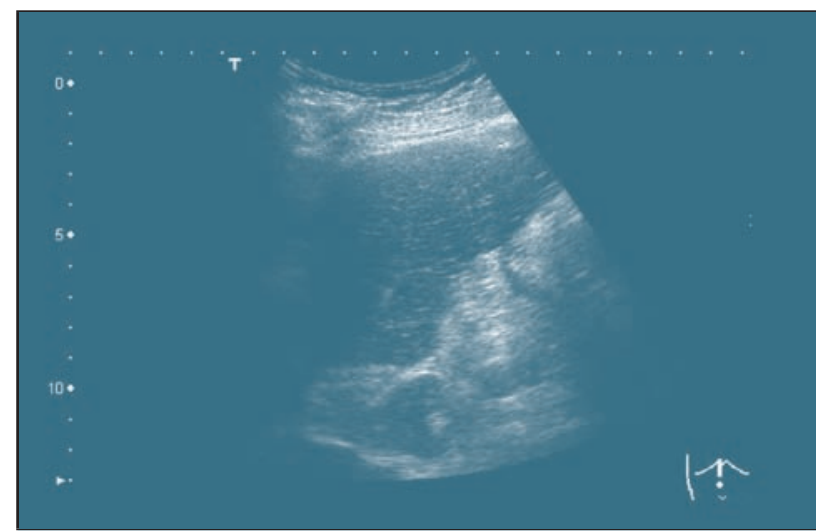

4 (b). B-mode US

Hepatic lesion was not recognized on B-mode sonogram. 
Maruyama et al. Contrast-Enhanced Ultrasonography: A Recent Application for the Diagnosis and Treatment...

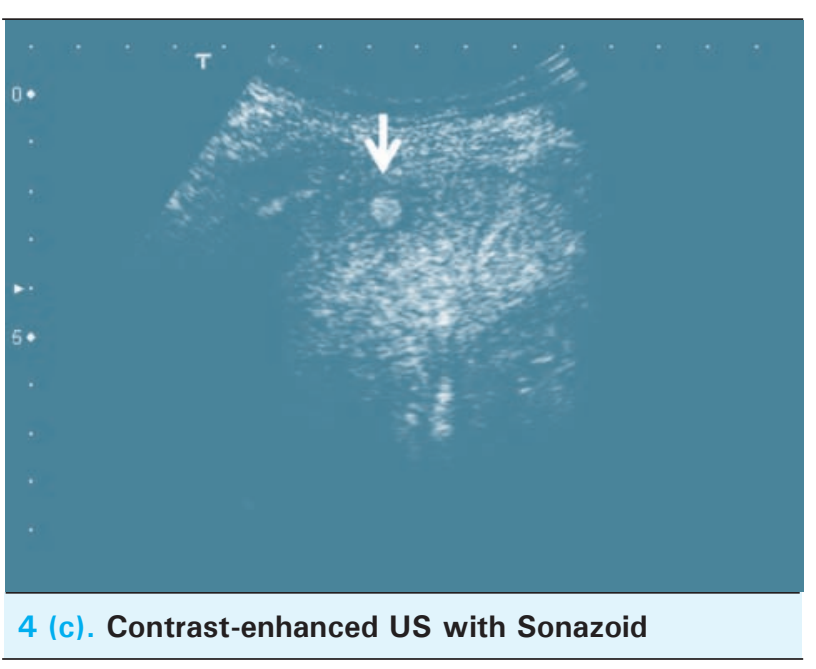

Hepatic lesion which corresponded to CT finding was demonstrated on contrast-enhanced US image with Sonazoid (arrow).

deposition that affects the evaluation of contrastenhanced CT findings. Minami et al. reported that contrast-enhanced harmonic US with Levovist had a significantly higher sensitivity in depicting residual blood flow in HCC about one week after TACE than dynamic CT and dynamic MR imaging: contrastenhanced US: 38 of 44 (86\%) lesions, dynamic CT: 19 of 44 (43\%) lesions, dynamic MR imaging: 10 of $20(50 \%)$ lesions. ${ }^{98}$ They also added that the contrast-enhanced US findings are predictive for local recurrence of HCC in the clinical course after treatment. Morimoto et al. compared the results of contrast-enhanced US with histologic findings, and sensitivity and specificity for discerning viable and nonviable HCC after TACE in 29 HCC nodules were $100 \%$ and $81 \%$, respectively. ${ }^{99}$ With the use of SonoVue, Pompili et al. described that contrastenhanced US resulted in diagnostic agreement in $53 / 56$ cases $(94.6 \%)$, with sensitivity and specificity of $87.0 \%$ and $98.4 \%$, respectively, after nonsurgical treatments for HCC (PEI, RFA, TACE, TACE followed by PEI, RFA followed by PEI), compared with contrast-enhanced CT findings. ${ }^{100}$

As mentioned above, the diagnostic ability with the assessment of therapeutic response in HCC is now sufficient, and is equivalent to contrast-enhanced CT findings. Although there are some limitations that the performance of US examination depends on the operator's skill, location of the tumor and system capability, contrast-enhanced US would play a major role in evaluation of the therapeutic effect of HCC. The recent developments in this technology would allow contrast-enhanced US to be positioned as the standard method for evaluation of the therapeutic effect in many HCC patients.

In conclusion, US has made amazing strides in the last decades because of digital technology progress, and it will continue to grow. The advancement of imaging methods is expected to support the clinical management of patients with HCC.

\section{REFERENCES}

1. Bosch FX, Ribes J, Borras J. Epidermiology of primary liver cancer. Semin Liver Dis 1999;19:271-85.

2. Okuda K. Hepatocellular carcinoma. J Hepatol 2000;32:S22537.

3. Kremkau FW. Diagnostic ultrasound: Principles and Instruments. 4th Ed. Philadelphia:WB Saunders;1993.

4. Maruyama H, Yoshikawa M, Yokosuka O. Current role of ultrasound for the management of hepatocellular carcinoma. World J Gastroenterol 2008;21:1710-9.

5. Goldberg BB. Ultrasound contrast agents. Martin Dunitz Ltd.;1997.

6. Ohto M, Karasawa E, Tsuchiya Y, et al. Ultrasonically guided percutaneous contrast medium injection and aspiration biopsy using a real-time puncture transducer. Radiology 1980;136:171-6.

7. Sheu JC, Huang GT, Chen DS, et al. Small hepatocellular carcinoma: Intratumor ethanol treatment using new needle and guidance systems. Radiology 1987;163:43-8.

8. Nelson TR, Pertorius DH. Three-dimensional ultrasound imaging. Ultrasound Med Biol 1998;24:1243-70.
9. Downey DB, Fenster A, Williams JC. Clinical utility of threedimensional US. Radiographics 2000;20:559-71.

10. Wells PNT, Halliwell M, Skidmore R, et al. Tumor detection by ultrasonic Doppler blood-flow signals. Ultrasonics 1977;15:231-6.

11. Merritt CRB. Doppler Color Flow Imaging. J Clin Ultrasound 1987;15:591-7.

12. Grant EG, Tessler FN, Perrella RR. Clinical Doppler Imaging. AJR Am J Roentgenol 1988;152:707-17.

13. Taylor KJW, Ramos I, Morse SS, et al. Focal liver masses: Differential diagnosis with pulsed Doppler US. Radiology 1987;164:643-7.

14. Mitchell DG. Color Doppler Imaging: Principles, Limitations, and Artifacts. Radiology 1990;177:1-10.

15. Tanaka S, Kitamura T, Fujita M, et al. Color Doppler flow imaging of liver tumors. AJR Am J Roentgenol 1990;154:509-14.

16. Foley WD, Erickson SJ. Color Doppler Flow Imaging. AJR Am J Roentgenol 1991;156:3-13.

17. Nino-Murcia M, Ralls PW, Jeffrey RB Jr, et al. Color flow Doppler characterization of focal hepatic lesions. AJR Am J Roentgenol 1992;159:1195-7. 
Maruyama et al. Contrast-Enhanced Ultrasonography: A Recent Application for the Diagnosis and Treatment...

18. Rubin JM, Bude RO, Carson PL, et al. Power Doppler US: a potentially useful alternative to mean frequency-based color Doppler sonography. Radiology 1994;190:853-6.

19. Choi BI, Kim TK, Han JK, et al. Power versus conventional color Doppler sonography: comparison in the depiction of vasculature in liver tumors. Radiology 1996;200:55-8.

20. Lencioni R, Pinto F, Armillotta N, et al. Assessment of tumor vascularity in hepatocellular carcinoma: comparison of power Doppler US and color Doppler US. Radiology 1996;201:3538.

21. Gaiani S, Volpe L, Piscaglia F, et al. Vascularity of liver tumours and recent advances in Doppler ultrasound. J Hepatol 2001;34:474-82.

22. Gramiak R, Shah PM. Echocardiography of the aortic root. Invest. Radiol 1968;3:356-66.

23. Kremkau FW, Gramiak R, Carstensen EL, Shah PM, Kramer DH. Ultrasonic detection of cavitation at catheter tips. Am J Roentgenol Radium Ther Nucl Med. 1970;110:177-83.

24. Ziskin MC, Bonakdapour A, Weinstein DP, et al. Contrast agents for diagnostic ultrasound. Invest Radiol 1972;7:500-5.

25. Goldberg BB. Ultrasonic cholangiography. Radiology 1976;118:401-4.

26. Matsuda Y. Yabuuchi I. Hepatic tumors: US contrast enhancement with $\mathrm{CO} 2$ microbubbles. Radiology 1986;161:701-5.

27. Kudo M, Tomita S, Tochio H, et al. Small hepatocellular carcinoma: diagnosis with US angiography with intraarterial CO2 microbubbles. Radiology 1992;182:155-60.

28. Ophir J, Parker KJ. Contrast agents in diagnostic ultrasound. Ultrasound Med Biol 1989;15:319-33.

29. Burns PN. Harmonic imaging with ultrasound contrast agents. Clin Radiol 1996;51:Suppl.1,50-5.

30. Burns PN, Wilson SR, Simpson DH. Pulse inversion imaging of liver blood flow: Improved method for characterizing focal masses with microbubble contrast. Invest Radiol 2000;35:5871.

31. Hauff P, Fritzsch T, Reinhardt M, et al. Delineation of experimental liver tumors in rabbits by a new ultrasound contrast agent and stimulated acoustic emission. Invest Radiol 1997;32:94-9.

32. Blomley MJ, Albrecht T, Cosgrove DO, et al. Stimulated acoustic emission in liver parenchyma with Levovist. Lancet 1998;351:568.

33. Kamiyama N, Moriyasu F, Mine Y, et al. Analysis of flash echo from contrast agent for designing optimal ultrasound diagnostic systems. Ultraound Med Biol 1998;25:411-20.

34. Maruyama H, Matsutani S, Saisho H, et al. Grey-scale contrastenhancement in rabbit liver with DMP115 at different acoustic power levels. Ultrasound Med Biol 2000;26:1429-38.

35. Bauer A, Solbiati L, Weissman N. Ultrasound imaging with SonoVue: low mechanical index real-time imaging. Acad Radiol 2002;9:Suppl2,S282-4.

36. Maruyama H, Matsutani S, Saisho H, et al. Extra-low acoustic power harmonic images of the liver with perflutren: novel imaging for real-time observation of liver perfusion. J Ultrasound Med 2003;22:931-8.

37. Albrecht $\mathrm{T}$, Oldenburg A, Hohmann J, et al. Imaging of liver metastases with contrast-specific low-MI real-time ultrasound and SonoVue. Eur Radiol 2003;13:Suppl3,N79-86.

38. Greis C. Technology overview: SonoVue (Bracco, Milan). Eur Radiol 2004;14:S11-5.

39. Numata K, Tanaka K, Kiba T, et al. Contrast-enhanced, wide-band harmonic gray scale imaging of hepatocellular carcinoma. Correlation with helical computed tomographic findings. J Ultrasound Med 2001;20:89-98.

40. Giorgio A, Ferraioli G, Tarantino L, et al. Contrast-enhanced sonographic appearance of hepatocellular carcinoma in patients with cirrhosis: Comparison with contrast-enhanced helical CT appearance. AJR Am J Roentgenol 2004;183:131926 .

41. Bolondi L, Gaiani S, Celli N, et al. Characterization of small nodules in cirrhosis by assessment of vascularity: The problem of hypovascular hepatocellular carcinoma. Hepatology 2005;42:27-34.

42. Kim TK, Choi BI, Han JK, et al. Hepatic tumors: Contrast agent-enhancement patterns with pulse-inversion harmonic US. Radiology 2000;216:411-7.

43. von Herbay A, Vogt C, Haussinger D. Pulse inversion sonography in the early phase of the sonographic contrast agent Levovist: differentiation between benign and malignant focal liver lesions. J Ultrasound Med 2002;21:1191-200.

44. Furuse J, Nagase M, Ishii $H$, et al. Contrast enhancement patterns of hepatic tumours during the vascular phase using coded harmonic imaging and Levovist to differentiate hepatocellular carcinoma from other focal lesions. Br J Radiol 2003;76:385-92.

45. von Herbay A, Vogt C, Haussinger D. Late-phase pulseinversion sonography using the contrast agent Levovist: differentiation between benign and malignant focal lesions of the liver. AJR Am J Roentgenol 2002;179:1273-9.

46. von Herbay A, Vogt C, Haussinger D. Differentiation between benign and malignant hepatic lesions: utility of color stimulated acoustic emission with the microbubble contrast agent Levovist. J Ultrasound Med 2004;23:207-15.

47. Bryant $\mathrm{TH}$, Blomley $\mathrm{MJ}$, Albrecht $\mathrm{T}$, et al. Improved characterization of liver lesions with liver-phase uptake of liver-specific microbubbles: Prospective multicenter study. Radiology 2004;232:799-809.

48. Dietrich CF, Ignee A, Trojan J, et al. Improved characterization of histologically proven liver tumours by contrast enhanced ultrasonography during the portal venous and specific late phase of SHU 508A. Gut 2004;53:401-5.

49. von Herbay A, Vogt C, Willers R, et al. Real-time imaging with the sonographic contrast agent SonoVue: differentiation between benign and malignant hepatic lesions. J Ultrasound Med 2004;23:1557-68.

50. Nicolau C, Vilana R, Catala V, et al. Importance of evaluating all vascular phases on contrast-enhanced sonography in the differentiation of benign from malignant focal liver lesions. AJR Am J Roentgenol 2006;186:158-67. 
Maruyama et al. Contrast-Enhanced Ultrasonography: A Recent Application for the Diagnosis and Treatment...

51. Kim SH, Lee JM, Lee JY, et al. Value of contrast-enhanced sonography for the characterization of focal hepatic lesions in patients with diffuse liver disease: Receiver operating characteristic analysis. AJR American J Roentgenol 2005;184:1077-84.

52. Kudo M. Imaging diagnosis of hepatocellular carcinoma and premalignant/borderline lesions. Semin Liver Dis 1999;19:297-309.

53. Hayashi M, Matsui O, Ueda K, et al. Progression to hypervascular hepatocellular carcinoma: correlation with intranodular blood supply evaluated with CT during intraarterial injection of contrast material. Radiology 2002;225:143-9.

54. Roncalli M, Roz E, Coggi G, et al. The vascular profile of regenerative and dysplastic nodules of the cirrhotic liver: implication for diagnosis and classification. Hepatology 1999;30:1174-8.

55. International Working Party. Terminology of nodular hepatocellular lesions. Hepatology 1995;22:983-9.

56. Borzio M, Fargion S, Borzio F, et al. Impact of large regenerative, low grade and high grade dysplastic nodules in hepatocellular carcinoma development. J Hepatol 2003;39:20814.

57. Yoshizumi H, Maruyama H, Okugawa $\mathrm{H}$, et al. How to characterize non-hypervascular hepatic nodules on contrast-enhanced computed tomography in chronic liver disease: Feasibility of contrast-enhanced ultrasound with a microbubble contrast agent. J Gastroenterol Hepatol 2007. DOI: doi:10.1111/j.1440-1746.2007.05184.x.

58. KimSR, Maekawa Y,Ninomiya T, etal. Multiplehypervascular liver nodules in a heavy drinker of alcohol. J Gastroenterol Hepatol 2005;20:795-9.

59. Maruyama H, Matsutani S, Kondo F, et al. Ring-shaped appearance on liver-specific image with Levovist: a characteristic enhancement pattern for hypervascular benign nodule in the liver of heavy drinkers. Liver Int 2006;26:68894.

60. Blomley MJ, Albrecht T, Cosgrove DO, et al. Improved imaging of liver metastases with stimulated acoustic emission in the late phase of enhancement with the US contrast agent SHU 508A: Early experience. Radiology 1999;210:409-16.

61. Harvey CJ, Blomley MJ, Eckersley RJ, et al. Pulse-inversion mode imaging of liver specific microbubbles: improved detection of subcentimetre metastases. Lancet 2000;355:8078 .

62. Harvey CJ, Blomley MJ, Eckersley RJ, et al. Hepatic malignancies: Improved detection with pulse-inversion US in late phase of enhancement with SHU 508A-Early experience. Radiology 2000;216:903-8.

63. Kim TK, Choi BI, Hong HS, et al. Improved imaging of hepatic metastases with delayed pulse inversion harmonic imaging using a contrast agent SHU 508A: Preliminary study. Ultrasound Med Biol 2000;26:1439-44.

64. Forsberg F, Piccoli CW, Liu JB, et al. Hepatic tumor detection: MR imaging and conventional US versus pulse-inversion harmonic US of NC100100 during its reticuloendothelial system-specific phase. Radiology 2002;222:824-9.

65. Maruyama H, Matsutani S, Saisho H, et al. Real-time bloodpool images of contrast enhanced ultrasound with Definity in the detection of liver tumour nodules in the liver. Br J Radiol 2005;78:512-8.

66. Rankin RN, Fenster A, Downey DB, et al. Three-dimensional sonographic reconstruction: techniques and diagnostic applications. AJR Am J Roentgenol 1993;161:695-702.

67. Picot PA, Rickey DW, Mitchell R, Rankin RN, Fenster A Three-dimensional colour Doppler imaging. Ultrasound Med Biol 1993;19:95-104.

68. Downey DB, Fenster A. Vascular imaging with a threedimensional power Doppler system. AJR Am J Roentgenol 1995;165:665-8.

69. Ritchie CJ, Edwards WS, Mack LA, et al. Three-dimensional ultrasonic angiography using power-mode Doppler. Ultrasound Med Biol 1996;22:277-86.

70. Okuda K. Hepatocellular carcinoma: Recent progress Hepatology 1992;15:948-63.

71. Bruix J, Sherman M, Llovet J, et al., EASL Panel of Experts on HCC. Clinical management of hepatocellular carcinoma. Conclusions of the Barcelona-2000 EASL conference. J Hepatol 2001;35:421-30.

72. Ebara M, Ohto M, Sugiura N, et al. Percutaneous ethanol injection for the treatment of small hepatocellular carcinoma. Study of 95 patients. Journal of Gastroenterol Hepatol 1990;5:616-26.

73. Shiina S, Tagawa K, Unuma T, et al. Percutaneous ethanol injection therapy for the treatment of hepatocellular carcinoma AJR Am J Roentgenol 1990;154:947-51

74. Livraghi T, Bolondi L, Lazzaroni S, et al. Percutaneous ethanol injection in the treatment of hepatocellular carcinoma in cirrhosis. A study on 207 patients. Cancer 1992;69:925-9.

75. Redvanly RD, Chezmar JL, Strauss RM, et al. Malignant hepatic tumors: Safety of high-dose percutaneous ethanol ablation therapy. Radiology 1993;188:283-5.

76. Goldberg SN, Gazelle GS, Solbiati L, et al. Radiofrequency tissue ablation: increased lesion diameter with a perfusion electrode. Acad Radiol 1996;3:636-44.

77. Solbiati L, Goldberg SN, Ierace T, et al. Hepatic metastases: Percutaneous radio-frequency ablation with cooled-tip electrodes. Radiology 1997;205:367-73.

78. Lencioni R, Bartolozzi C, Caramella D, et al. Treatment of small hepatocellular carcinoma with percutaneous ethanol injection: analysis of prognostic factors in 105 Western patients. Cancer 1995;76:1737-46

79. Ryu M, Shimamura Y, Kinoshita T, et al. Therapeutic results of resection, transcatheter arterial embolization and percutaneous ethanol injection in 3225 patients with hepatocellular carcinoma: a retrospective multicenter study. Jpn J Clin Oncol 1997;27:251-7.

80. Ebara M, Okabe S, Kita K, et al. Percutaneous ethanol injection for small hepatocellular carcinoma: Therapeutic efficacy based on 20-year observation. J Hepatol 2005;43:458-64. 
Maruyama et al. Contrast-Enhanced Ultrasonography: A Recent Application for the Diagnosis and Treatment...

81. Livraghi T, Goldberg SN, Lazzaroni S, et al. Small hepatocellular carcinoma: treatment with radiofrequency ablation versus ethanol injection. Radiology 1999;210:655-61.

82. Livraghi T, Lazzaroni S, Meloni F. Radiofrequency thermal ablation of hepatocellular carcinoma. Eur J Ultrasound 2001;13:159-66.

83. Lencioni RA, Allgaier HP, Cioni D, et al. Small hepatocellular carcinoma in cirrhosis: Randomized comparison of radiofrequency thermal ablation versus percutaneous ethanol injection. Radiology 2003;228:235-40.

84. Giorgio A, Tarantino L, Stefano G, et al. Percutaneous sonographically guided saline-enhanced radiofrequency ablation of hepatocellular carcinoma. AJR Am J Roentgenol 2003;181:479-84.

85. Takayasu K, Muramatsu Y, AsaiS, etal.CT fluoroscopyassisted needle puncture and ethanol injection for hepatocellular carcinoma: a preliminary study. AJR Am J Roentgenol 1999;173:1219-24.

86. Sato M, Watanabe $\mathrm{Y}$, Tokui $\mathrm{K}$, et al. CT-guided treatment of ultrasonically invisible hepatocellular carcinoma. Am J Gastroenterol 2000;95:2102-6.

87. Schweiger GD, Brown BP, Pelsang RE, et al. CT fluoroscopy: technique and utility in guiding biopsies of transiently enhancing hepatic masses. Abdom Imaging 2000;25:81-5.

88. Shibata T, Iimuro Y, Yamamoto $\mathrm{Y}$, et al. CT-guided transthoracic percutaneous ethanol injection for hepatocellular carcinoma not detected with US. Radiology 2002;223:115-20.

89. Kickuth R, Laufer U, Hartung G, et al. CT fluoroscopy assisted puncture of thoracic and abdominal masses: a randomized trial. Clin Radiol 2002;57:188-92.

90. Solomon SB, Bohlman ME, Choti MA. Percutaneous gadolinium injection under MR guidance to mark target for CT-guided radiofrequency ablation. J Vasc Interv Radiol 2002;13:419-21.

91. Maruyama H, Kobayashi S, Yoshizumi H, et al. Application of percutaneous US-guided treatment for ultrasonically invisible hypervascular hepatocellular carcinoma using microbubble contrast agent. Clin Radiol 2007;62:668-75.

92. MorelDR, Schwieger I,Hohn L, etal. Human pharmacokinetics and safety evaluation of SonoVue, a new contrast agent for ultrasound imaging. Invest Radiol 2000;35:80-5.
93. Maruyama H, Takahashi M, Ishibashi $\mathrm{H}$ et al. Ultrasoundguided treatments under low acoustic power contrast harmonic imaging for hepatocellular carcinomas undetected by B-mode ultrasonography. Liver Int., in press.

94. Bartolozzi C, Lencioni R, Ricci P, et al. Hepatocellular carcinoma treatment with percutaneous ethanol injection: Evaluation with contrast-enhanced color Doppler US. Radiology 1998;209:387-93.

95. Choi D, Lim HK, Kim SH, et al. Hepatocellular carcinoma treated with percutaneous radio-frequency ablation: Usefulness of power Doppler US with a microbubble contrast agent in evaluating therapeutic response-Preliminary results. Radiology 2000;217:558-63.

96. Wen $\mathrm{YL}$, Kudo $\mathrm{M}$, Zheng RQ, et al. Radiofrequency ablation of hepatocellular carcinoma: Therapeutic response using contrast-enhanced coded phase-inversion harmonic sonography. AJR Am J Roentgenol 2003;181:57-63.

97. Meloni MF, Goldberg SN, Livraghi T, et al. Hepatocellular carcinoma treated with radiofrequency ablation: Comparison of pulse inversion contrast-enhanced harmonic sonography, contrast-enhanced power Doppler sonography, and helical CT. AJR Am J Roentgenol 2001;177:375-80.

98. Minami Y, Kudo M, Kawasaki T, et al. Chemoembolization of hepatocellular carcinoma: usefulness of coded phaseinversion harmonic sonography. AJR Am J Roentgenol 2003;180:703-8.

99. Morimoto M, Shirato K, Sugimori K, et al. Contrast-enhanced harmonic gray-scale sonographic-histologic correlation of the therapeutic effects of transcatheter arterial chemoembolization in patients with hepatocellular carcinoma. AJR Am J Roentgenol 2003;181:65-9.

100.Pompili M, Riccardi L, Covino M, et al. Contrast-enhanced gray-scale harmonic ultrasound in the efficacy assessment of ablation treatments for hepatocellular carcinoma. Liver Int 2005;25:954-61.

101. Kim CK, Choi D, Lim HK, et al. Therapeutic response assessment of percutaneous radio frequency ablation for hepatocellular carcinoma: Utility of contrast-enhanced agent detection imaging. Eur J Radiol 2005;56:66-73.

102.Solbiati L, Goldberg SN, Ierace T, et al. Radio-frequency ablation of hepatic metastases: Postprocedural assessment with a US microbubble contrast agent - Early experience. Radiology 1999:211:643-9. 